\title{
Why Here? Why Now? Why JAMS?
}

\section{Billy Tringali}

The goal of the Journal of Anime and Manga Studies is to provide a space for academics, students, and independent researchers examining the field of anime, manga, cosplay, and fandom studies to access high-quality research about these topics and share their research with others. But how did this journal come to be? Why make this journal open-access?

As this is the first volume and the first issue of the Journal of Anime and Manga Studies, I feel that answering these questions will make for a perfect introduction to this journal.

\section{What sparked JAMS?}

In April of 2017, I was fortunate enough to visit the Kyoto International Manga Museum. I had been a fan of anime since I was a child and had built some of the most wonderful friendships of my life through cosplay and conventions in the New England area.

Wandering the museum, surrounded by shelves upon shelves of manga, I came across a message from the museum's Executive Director, Aramata Hiroshi. In concluding his message, Aramata noted "It is our ultimate goal to be a place that protects the neglected, vanishing manga, and revives them as cultural properties. I too am also imbued with this sense of 'burning' and will endeavor to do all I can."i Perhaps it is dramatic to say, but reading this quote, surrounded on all sides by manga, I too wanted to do all I could for anime and manga as an art form. 
I wasn't an artist, and I didn't know what I could do to support this art form in that moment, but a 'burning' was imbued in me that day, a burning I carried with me into my graduate program.

\section{Why is JAMS open-access?}

In August of 2017, I started a Master's of Science in Library and Information Science at the University of Illinois at Urbana-Champaign. The UIUC library is one of the largest in the United States, so I had millions of resources at my fingertips; that turned out to be a very fortunate thing. Anime and manga studies is a rich, interdisciplinary subject, meaning papers that analyze anime and manga are published across a variety of subjects, and in a variety of monographs and journals. In the midst of taking courses on open-access and academic librarianship, it dawned on me that researchers outside of higher education or at smaller universities may not have access to the incredible scholarship so many anime and manga studies' researchers are creating.

I felt that 'burning' in me rise in a way I knew I could act on.

I want scholarship about anime and manga to be accessible to everyone, regardless of university affiliation. JAMS is the action taken to help achieve this goal.

\section{How did JAMS come to be published through the Illinois Open Publishing Network?}

The Illinois Open Publishing Network (IOPN) is "a set of digital publishing initiatives that are hosted and coordinated at the University of Illinois at UrbanaChampaign Library." ${ }^{i i}$ After learning that IOPN was accepting proposals for projects, I approached Dr. Maria Bonn at the University of Illinois' iSchool. 
"I'd like to start an open-access journal focused on anime and manga."

Maria was silent for a moment, then reached into her purse. Taking out a Studio Ghibli-themed wallet, she said, "This project is important and worthwhile.” Since these starting words, Maria has continued to be an invaluable resource to the journal as a member of the Editorial Board. This conversation launched a year-long notes process, during which time I collaborated with and owe thanks to Maria Bonn, Harriet Green, Merinda Hensley, and Janet Swatscheno for their feedback and guidance. Guidelines for the journal were written, edited, and finalized over the course of this year, all based on suggestions from the Committee on Publication Ethics. iii These guidelines can be read in JAMS “About the Journal" page. I also presented at two, national conferences with the hope of sparking interest in this project, building an Editorial Board, and receiving feedback from popular culture scholars about the need for this type of journal. The proposal for JAMS to be published through IOPN was approved in the summer of 2019.

Getting JAMS published through IOPN was an amazing accomplishment, and the University of Illinois' Library's Scholarly Communication \& Publishing Unit has my endless thanks for their consistent help in getting this first issue of JAMS published.

\section{Who else needs to be thanked?}

My extreme gratitude must again be given to the entirety of the University of Illinois' Library's Scholarly Communication \& Publishing Unit, with specific thanks to Dan Tracy and Sara Benson.

I must also thank the incredible members of JAMS' Editorial Board, whose guidance has been essential in planning out this first issue. Thank you to Brent Allison, 
Maria Bonn, Kay K. Clopton, Mark Gellis, Andrea Horbinski, Frenchy Lunning, and Elizabeth Wickes. Special thanks must also be extended to JAMS' Copy Editor, Jessica Parent, whose time and effort during the publication process is so very appreciated.

Thank you to all the authors who submitted to JAMS, and all that are considering submission to this journal. Thanks must also be extended to the amazing peer reviewers who volunteered their time for JAMS. Without all their help, this journal never would have come together.

Finally, I must thank Leora Lev, the professor that first sparked my passion for popular culture scholarship.

I hope the Journal of Anime and Manga Studies can exist as a space that publishes high-quality scholarship about anime, manga, cosplay, and their fandoms. I hope that JAMS can bring visibility to the deeper meanings, understandings, and cultural significance of anime, manga, cosplay, and their fandoms. I hope that, in making JAMS open-access scholarship about anime and manga can be accessible to everyone, regardless of university affiliation. As Aramata Hiroshi and the Kyoto International Museum of Manga imbued a burning desire in me, I hope that the papers you will read in this journal imbue the same sense in you to do all you can for this fantastic art form.

Thank you for reading the first issue of the Journal of Anime and Manga Studies.

With warmth,

Billy Tringali

Editor-In-Chief 
'Hiroshi Aramata, "Message from the Executive Director," Kyoto Internationa Manga Museum, Accessed September 5, 2020, https://www.kyotomm.jp/en/about/greeting/

ii Illinois Open Publishing Network, “About IOPN,"IOPN, Accessed September 5, 2020, https://iopn.library.illinois.edu/iopn-mission/

iii COPE Council, OASPA, DOAJ, and WAME, Principles of Transparency and Best Practice in Scholarly Publishing. Version 3 January 2018, https://doi.org/10.24318/cope.2019.1.12

\section{Bibliography}

Aramata, Hiroshi. "Message from the Executive Director." Kyoto International Manga Museum. Accessed September 5, 2020. https://www.kyotomm.jp/en/about/greeting/

COPE Council, OASPA, DOAJ, and WAME. Principles of Transparency and Best Practice in Scholarly Publishing. Version 3 January 2018. https://doi.org/10.24318/cope.2019.1.12

Illinois Open Publishing Network. “About IOPN.” IOPN. Accessed September 5, 2020. https://iopn.library.illinois.edu/iopn-mission/ 